\title{
ЗАКОНОМЕРНОСТИ ИЗМЕНЕНИЯ ОСНОВНЫХ ПАРАМЕТРОВ ПРОМЫШЛЕННОЙ ПАЧКИ ГОРЮЧЕГО СЛАНЦА ЭСТОНСКОГО МЕСТОРОЖДЕНИЯ
}

Закономерности изменения мощности промышленной пачки, теплоты сгорания и удельного выхода горючего сланца, а также коррелятивную связь между этими показателями определяли по многочисленным данным геологоразведки, маркшейдерской службы и шахтной геологии, полученным в течение многих лет наблюдений и замеров на Эстонском и Ленинградском месторождениях. Это оказалось возможным благодаря характерным для промышленной пачки литологическим особенностям, устойчивым на расстоянии десятков и сотен километров, несмотря на весьма сложное ее строение (рис. 1).

По данным геолого-маркшейдерских замеров, проведенных в горных выработках действующих шахт и разрезов, а также по данным геологоразведки на площадях разведанных запасов установлено, что на

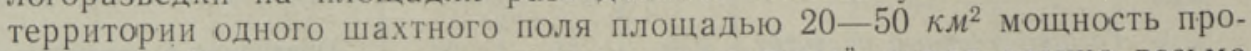
мышленной пачки, теплота сгорания и удельный выход сланца весьма выдержаны и изменяются незначительно. Наибольшее изменение этих показателей отмечается в субмеридиональном направлении: на протяжении $1 \kappa м$, например, теплота сгорания изменяется не более чем на $30 \kappa \kappa a \Omega / \kappa 2$, а полезная мощность промышленной пачки - на $1-2$ см. Однако характер и интенсивность изменений названных выше параметров промышленной пачки горючего сланца по всему месторождению можно выявить лишь с привлечением данных по всем разведочным и поисковым скважинам, пробуренным и опробованным Управлением геологии Эстонской ССР. Изолинии теплоты сгорания горной массы 'и удельного выхода условного топлива по промышленной пачке горючего сланца в объеме слоев $\mathrm{A}-\mathrm{F}_{2}$ в пределах всего месторождения проведены на рис. 2 на основе усредненных данных по скважинам, расположенным на площадях размером $4 \times 4$ км. (Усреднение данных по теплоте сгорания выполнено Кохтла-Ярвеской геолопической партией Управления геологии Эстонской ССР; В. А. Каттай, Т. И. Каттай и др.)

Теплота сгорания горной массы и уделыный выход условного топлива по промышленной пачке являются наиболее информативными показателями: по теплоте сгорания горной массы можно судить не только о характере природного изменения промышленной пачки, но и о качестве получаемого-при ее разработке товарного сланца (между этими показателями имеется прямая зависимость), а удельный выход условного топлива характеризует полезную мощность промышленной пачки и выход и качество сланца в виде натурального топлива. На основе этих показателей можно дать сопоставимые между собой оценки разных участков месторождения по количеству и качеству запасов сланца.

Из рис. 2 выясняется, что наибольшие значения теплоты сгорания 


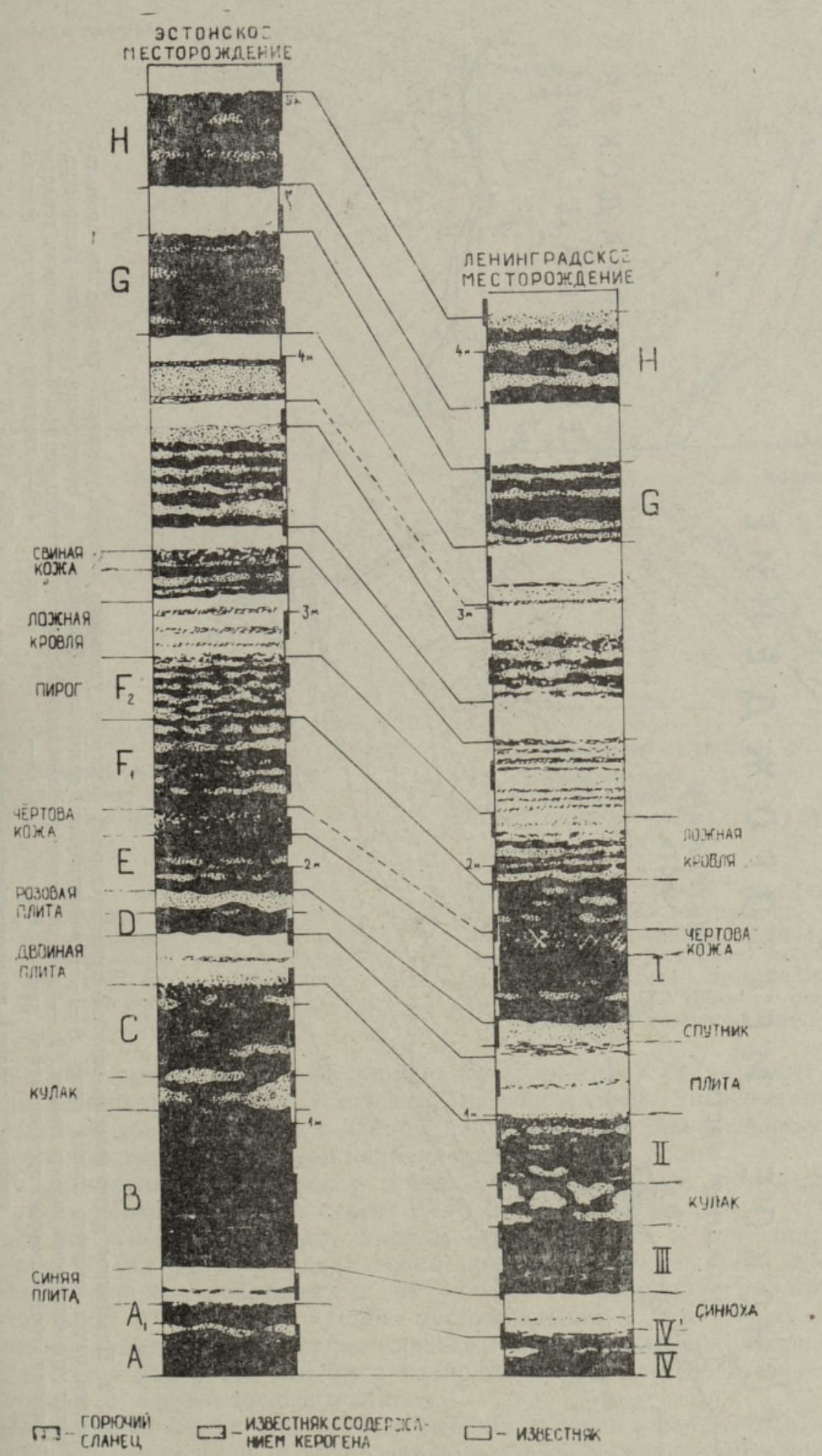

Рис. 1. Увязка разрезов промышленной пачки горючего сланца Эстонского и Ленинградского месторождений. 


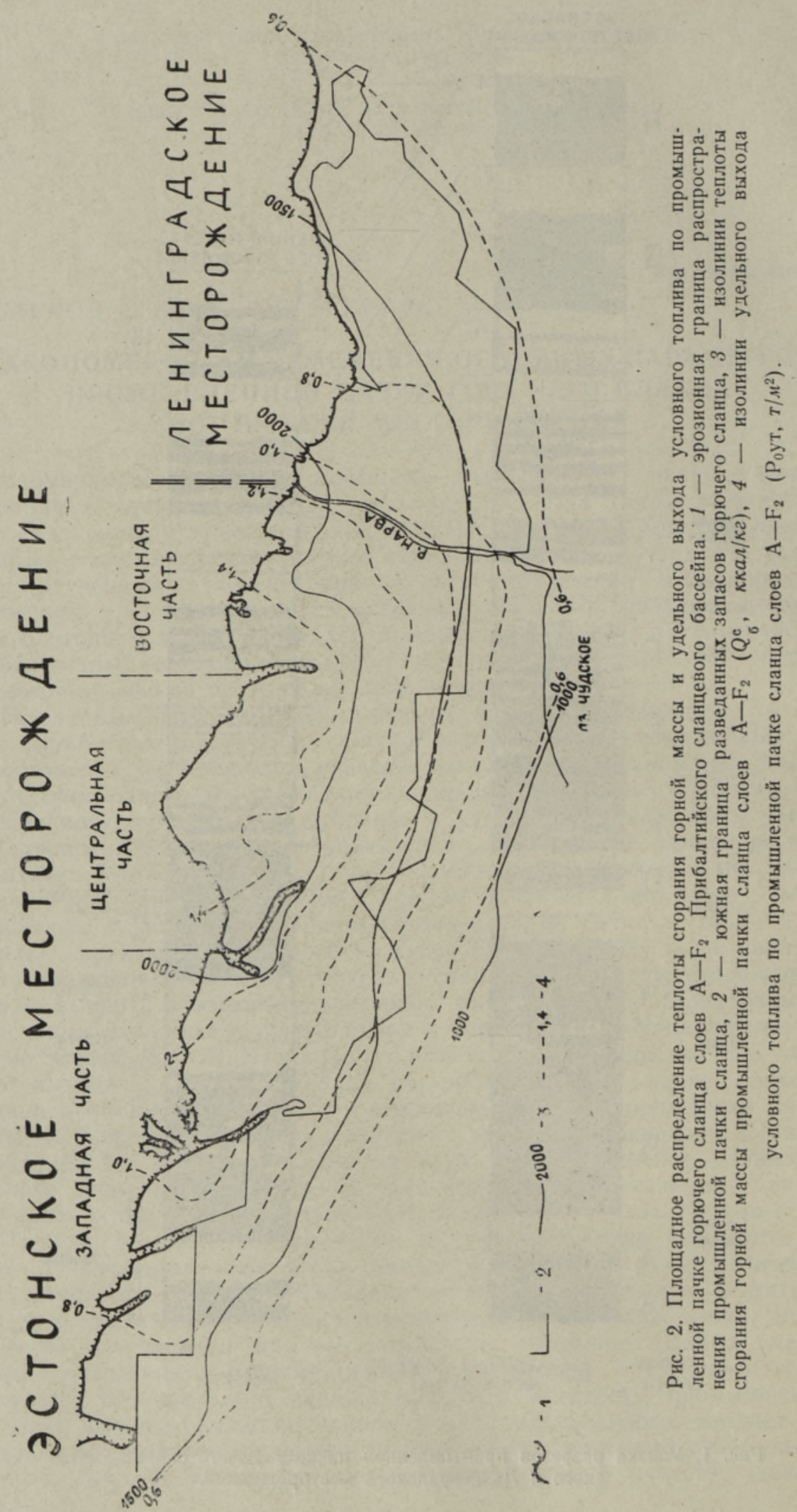




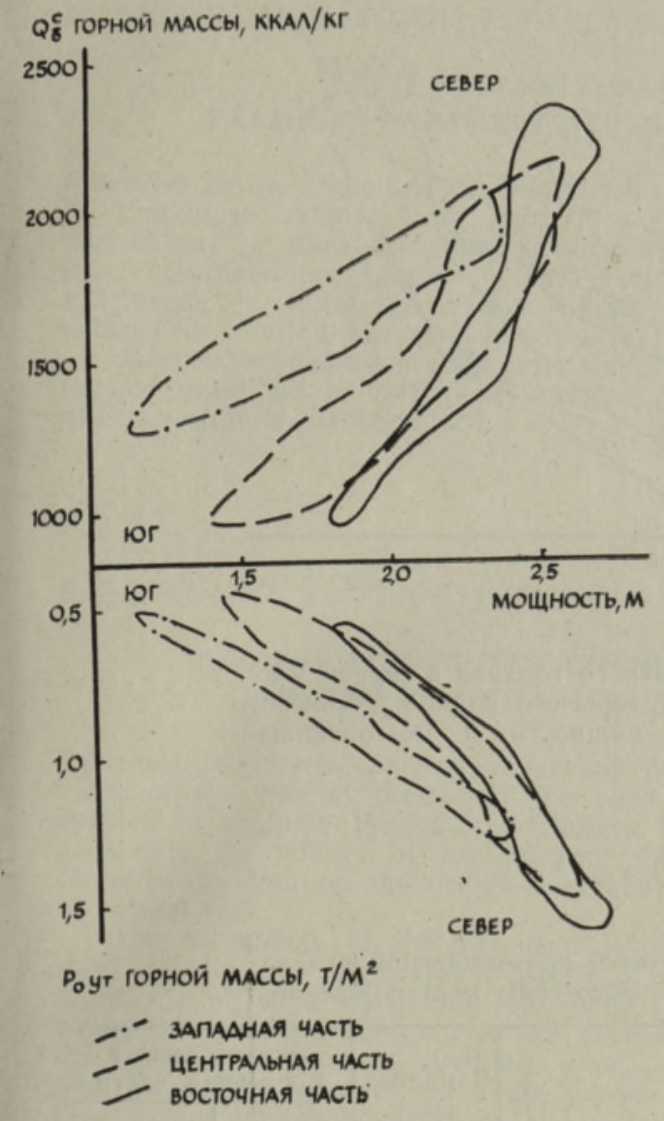

Рис. 3. Связь между мощностью, теплотой сгорания горной массы и удельным выходом условного топлива промышленной пачки слоев $\mathrm{A}-\mathrm{F}_{2}$ горючего сланца Эстонского месторождения.

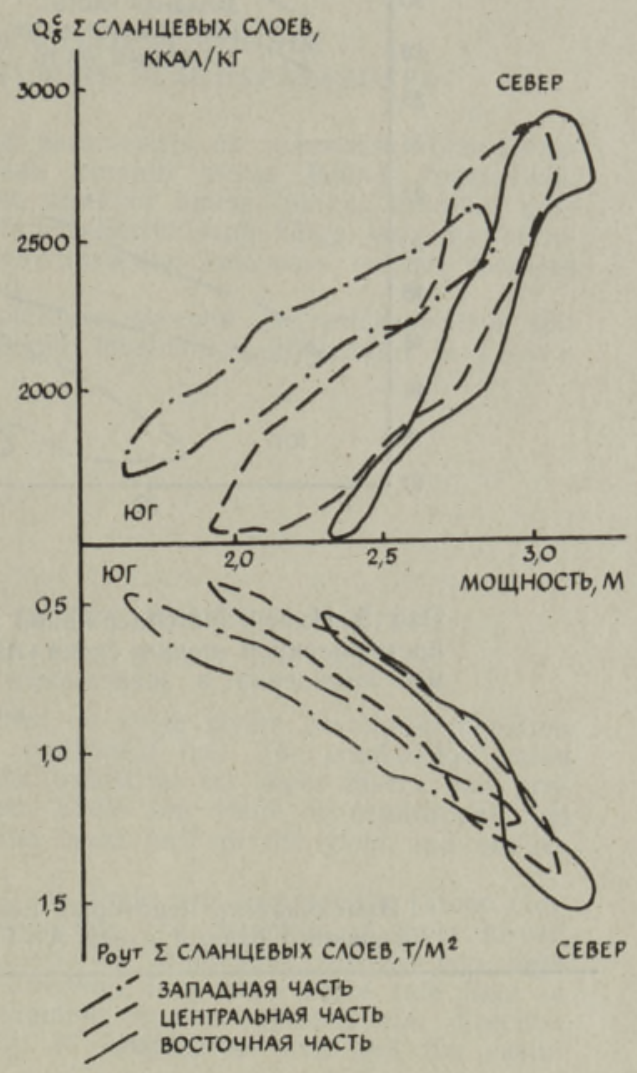

Рис. 4. Связь между мощностью, теплотой сгорания натурального топлива по суммарной мощности сланцевых слоев и удельным выходам условного топлива промышленной пачки слоев $\mathrm{A}-\mathrm{F}_{2}$ горючего сланца Эстонского месторождения.

и удельного выхода условного топлива промышленная пачка имеет на севере Центральной части Эстонского месторождения. Значения этих показателей убывают резко в южном направлении и значительно медленнее в восточном и западном направлениях.

Коррелятивные связи между основными параметрами промышленной пачки горючего сланца слоев $\mathrm{A}-\mathrm{F}_{2}$ изображены на рис. 3,4 и 5 по тем же исходным данным, которые использовались и при построении рис. 2 (на этих графиках точки коррелятивных связей между соответствующими показателями объединены в поля для Западной, Центральной и Восточной частей месторождения). Характерно, что мощность промышленной пачки горючего сланца, являясь основным генетическим фактором, как бы предопределяет количество и качество содержащегося в ней горючего сланца.

Представленные на рис. 2-5 изменения основных параметров промышленной пачки $\mathrm{A}-\mathrm{F}_{2}$ и коррелятивных связей между ними остаются сходными и в промышленных пачках слоев $\mathrm{A}-\mathrm{F}_{1}, \mathrm{~B}-\mathrm{F}_{1}$ и $\mathrm{B}-\mathrm{F}_{2}$. Конечно, в зависимости от разных объемов промышленной пачки наблюдается и различие в численных показателях, но тенденция изменения их в определенных направлениях в пределах месторождения 


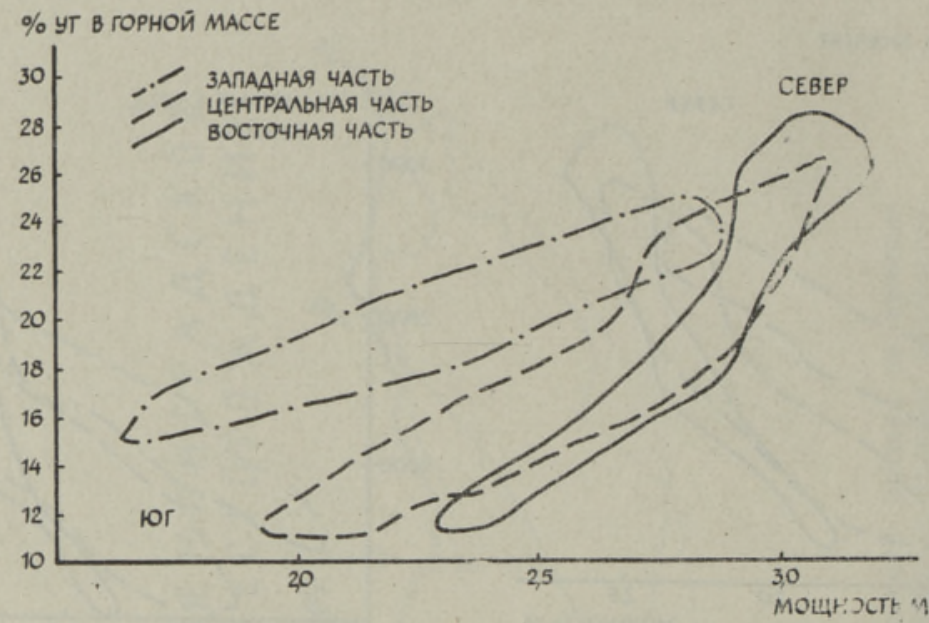

Рис. 5. Изменение содержання условного топлива в горной массе промышленной пачки слоев $\mathrm{A}-\mathrm{F}_{2}$ горючего сланца Эстонского месторождения в зависимости от мощности и местонахождения ее.

Изменчивость некоторых показателей промышленной пачки горючего сланца слоев $\mathrm{A}-\mathrm{F}_{2}$ на Эстонском месторождении

\begin{tabular}{|c|c|c|c|}
\hline \multirow{2}{*}{ Показатели } & \multirow{2}{*}{$\begin{array}{c}\text { Западная } \\
\text { часть }\end{array}$} & \multicolumn{2}{|c|}{$\begin{array}{c}\text { Центральная и } \\
\text { Восточная части }\end{array}$} \\
\hline & & Юr & Север \\
\hline $\begin{array}{l}\text { Мощность, см } \\
\text { Теплота сгорания натурального топлива на общую мощ- } \\
\text { ность пачки } Q_{\sigma}^{\mathrm{c}}, \kappa \kappa a л / \kappa 己\end{array}$ & $\begin{array}{r}165 \\
1300\end{array}$ & $\begin{array}{r}195 \\
1000\end{array}$ & $\begin{array}{r}320 \\
2300\end{array}$ \\
\hline $\begin{array}{l}\text { Теплота сгорания натурального топлива по суммарной } \\
\text { мощности сланцевых слоев пачки с учетом содержа- } \\
\text { ния известняковых включений } Q_{6}^{c}, \kappa \kappa a л / \kappa 己\end{array}$ & 1750 & 1500 & 2900 \\
\hline 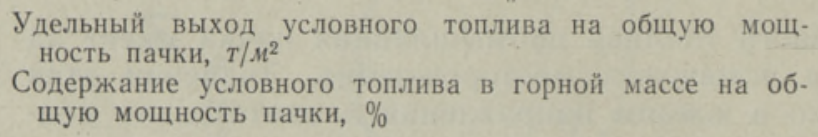 & $\begin{array}{l}0,50 \\
15\end{array}$ & $\begin{array}{l}0,45 \\
11\end{array}$ & 1,55 \\
\hline
\end{tabular}

сохраняется: в меридиональном направлении по сравнению с широтным теплота сгорания натурального топлива изменяется быстрее в $2,5-3,0$ раза, а удельный выход условного топлива - в $1,8-2,0$ раза. Крайние значения изменчивости основных параметров промышленной пачки горючего сланца Эстонского месторождения приведены в таблице.

Данные о распределении теплоты сгорания горной массы и удельного выхода условного топлива по площади, а также сведения о корреляционных зависимостях между основными параметрами промышленной пачки можно использовать для геолого-промышленной оценки отдельных участков месторождения и в целях выбора дальнейшего направления геологоразведочных работ. 


\section{EESTI POLEVKIVIMAARDLA TOOTSA KIHINDI PEAMISTE PARAMEETRITE MUUTUMISE SEADUSPÄRASUSED}

Pōlevkivi tootsa kihindi kõige informatiivsemad parameetrid on mäemassi kütteväärtus ja tingkütuse saagis. Neist esimene võimaldab hinnata tootsa kihindi looduslikku muutlikkust ja rikastusprodukti kvaliteeti, teine sisaldab tootsa kihindi kasuliku paksuse, naturaalkütuse saagise ja kvalitéedi näitajad. Eestis asub kōige kōrgema kütteväärtusega ja saagisega tootus kihind põlevkivimaardla keskosas; sellest lõunasse vähenevad näitajad kiiremini kui itta ja läände.

Mäemassi põhiparameetrite pindalalise jaotumuse skeemid ja nendevaheliste sõltuvuste graafikud on vajalikud maardla geoloogilis-tööstuslikul hindamisel ja geoloogiliste uuringute planeerimisel.

\section{S. BAUKOV, O. MOROZOV, T. TUBLI}

\section{REGULARITIES OF THE CHANGES IN THE MAIN PARAMETERS OF THE ESTONIAN INDUSTRIAL OIL SHALE LAYERS}

The most informative parameters of the industrial oil shale layers are the combustion value of the mineral mass and the yield of conditional fuel. The combustion value enables to evaluate the natural changes in the industrial oil shale layers and prognosticate the quality of the product obtained, while the yield of conditional fuel contains the data on the useful thickness of the layer and on the yield and quality of natural fuel.

The parameters of the industrial layers of oil shale are territorially rather constant, despite the complicated structure of the sequence. The Estonian oil shale deposit represents an area containing oil shale of a superior combustion quality and high yields, with indices changing in the southerly direction at a more rapid rate than in the westerly or easterly direction. Thus, for example, in the submeridional direction the combustion value of oil shale decreases by $30 \mathrm{kcal} / \mathrm{kg}$ per $\mathrm{km}$, and the useful thickness of the industrial layer by $1-2 \mathrm{~cm}$.

The correlative connections of the main parameters, as presented in Figures 3, 4 and 5 indicate clearly the character of the changes throughout the area, and they enable us to carry out geological and industrial forecasts as well as geological researches into the oil shale deposit discussed.

Произошла досадная ошибка. В статье «Ресурсы Эстонского месторождения ...» С. Баукова, О. Морозова, Т. Тубли, опубликованной в предыдущем номере ( $N_{2} 3$ за 1982 г.), помещен неправильный рисунок. Верный рисунок прилагаем ниже.

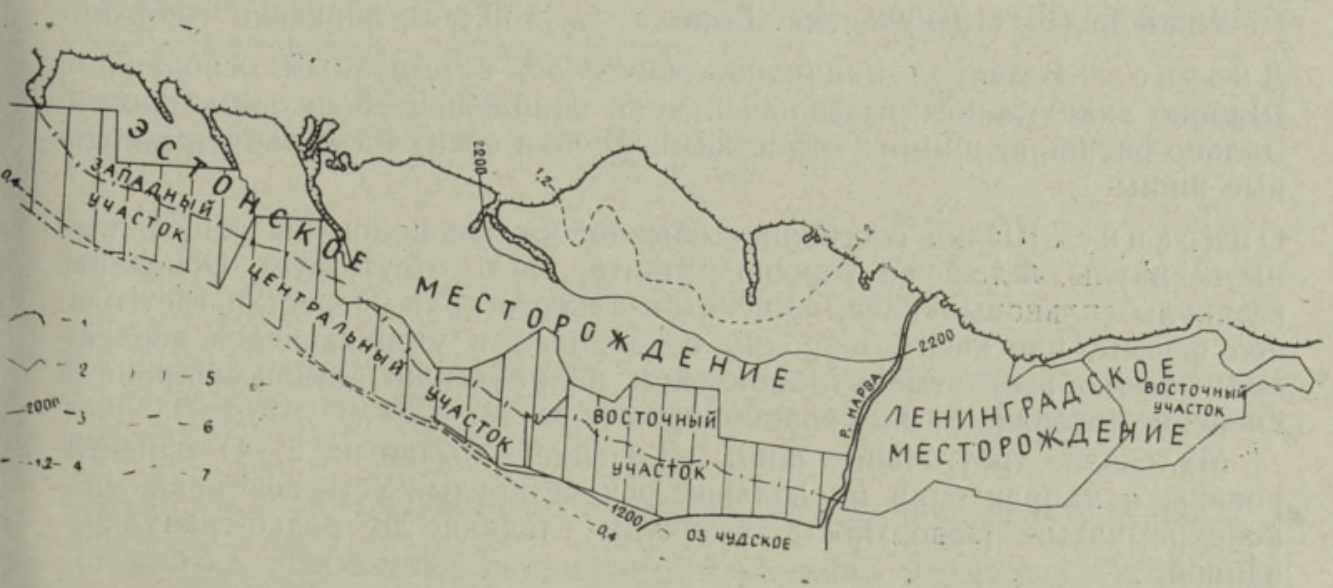

